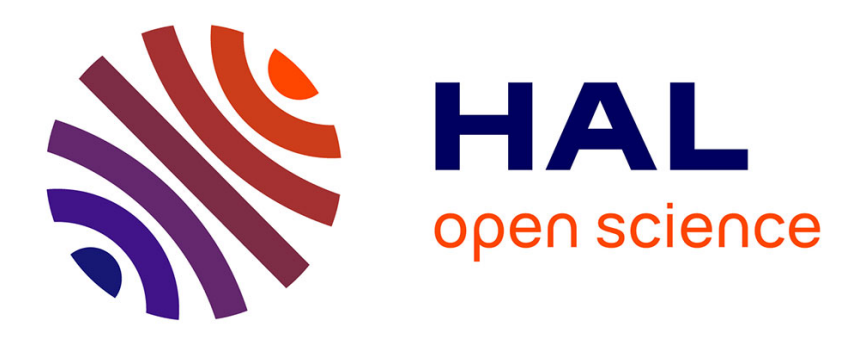

\title{
Paradigm shift in materials processing; the intelligent processing revolution
}

\author{
D. Apelian
}

\section{To cite this version:}

D. Apelian. Paradigm shift in materials processing; the intelligent processing revolution. Journal de Physique IV Proceedings, 1993, 03 (C7), pp.C7-1109-C7-1119. 10.1051/jp4:19937173 ～jpa-00251804

\section{HAL Id: jpa-00251804 https://hal.science/jpa-00251804}

Submitted on 1 Jan 1993

HAL is a multi-disciplinary open access archive for the deposit and dissemination of scientific research documents, whether they are published or not. The documents may come from teaching and research institutions in France or abroad, or from public or private research centers.
L'archive ouverte pluridisciplinaire HAL, est destinée au dépôt et à la diffusion de documents scientifiques de niveau recherche, publiés ou non, émanant des établissements d'enseignement et de recherche français ou étrangers, des laboratoires publics ou privés. 


\title{
Paradigm shift in materials processing; the intelligent processing revolution
}

\author{
D. APELIAN
}

Worcester Polytechnic Institute, 100 Institute Road, Worcester, MA 01609, U.S.A.

\begin{abstract}
During the last several decades, the importance of materials processing in the control of microstructure and materials properties has been recognized and, accordingly, the materials engineering community has dedicated much effort to studying the physics of the process. These endeavors have provided an understanding of the phenomena which are relevant. However, a paradigm shift is taking place in that the physics oriented approach to materials processing is being replaced by a control oriented approach. What is needed today is the ability to control the process and, thus, the trajectory of the controllable variables in a temporal space. Such a knowledge based approach to materials processing which requires understanding, sensors, and controls is the revolution taking place in the materials engineering field. The essence is a process which can learn and develop "intelligence" as it progresses. This address will present and discuss the basis and the need for a knowledge based approach to materials processing. Furthermore, specific industrial examples will be given to illustrate implementation of intelligent processing. Finally, the challenges ahead and the impediments we face as a community will also be addressed.
\end{abstract}




\section{INTRODUCTION}

The paradigm shift taking place in materials processing is one of transitioning from "physics oriented" to "process control" analyses. For many years the understanding of processes have been modeled and analyzed without taking into account process control needs. The latter brings about a different perspective, as well as a different rigor and methodology of approach.

Competitiveness is a crucial issue facing the manufacturing sector and certainly materials processing industries. An "awakening" began during the latter part of the 80 's...we discovered that productivity and quality are interlinked. Productivity increases directly gave rise to product quality increases. Deming's teachings have clearly demonstrated that controlling the process is the principle vehicle to ensure long term quality assurance.

During the last 2-3 years, a subtle revolution has taken place in our factory floors. Our processes are becoming more intelligent, i.e., our processes are "learning" from experience. Knowledge based engineering is being applied across the board. The results are impressive and the vista for the future is exciting.

In this keynote address, I'd like to take the opportunity to discuss and explain the basis of intelligent processing which will lead to a general discussion of knowledge engineering based processing. I will use a few examples to illustrate the application of these concepts in the world of materials processing, and lastly I would like to comment on the challenges we face as a community of materials processing engineers.

\section{INTELLIGENT PROCESSING}

The main concept of intelligent processing is to have on-line control during processing. Successful implementation of on-line control in materials processing industries involves full integration of design, procurement control of incoming components, manufacture, assembly, handling, packaging, and distribution.

There are three components:

1. Definitive understanding of the process. Process models need to be developed which will shed light on the critical and operative variables. 
2. Sensors that can interrogate the process to determine and measure various indices and the significant parameters...as borne out by physical and mathematical modeling or process understanding in general.

3. Armed with the above, process controls are established to compare the on-line feedback obtained from sensors with the process models. When deviations are observed, measures are taken to change the processing variables so that the operation will yield a "quality" product. Intrinsic to process control is a clear definition of the properties requireed at the end of each step and the relation of the intermediate properties to those specified.

The enormous benefits of incorporating process controls can be appreciated when one compares the practice of quality assurance with quality control. The former ensures that throughout each step of the process the measurements sensed are in agreement with the ideal, and if deviations are noted, changes are made. Quality control ensures that the produced component meets the established specifications...it is scrapped if it does not meet the specifications; a quality product is shipped at the expense of productivity. Thus the linkage between productivity and quality.

On-line controls are required at every step of the manufacturing process such that the final outcome does not even have to be inspected. The new traditional physics-oriented knowledge organization does not fit well within the framework of control theory and practice. Knowledge of materials processes as it has been organized is not control-oriented; rather it is physics-oriented. The control engineer requires the path of process variables during processing to be known so that a functional trajectory of the variables as a function of time can be described. Unfortunately, this trajectory is often now known.

The challenge of materials processing is to be able to control the process on an on-line basis, such that throughout the processing steps one can assure the quality and the specifications intended for the product.

\section{KNOWLEDGE ENGINEERING BASED PROCESSING}

Knowledge engineering is a domain of engineering science which deals with four stages of knowledge processing:organization, communication, creation, and utilization of knowledge. Organization consists of 
collecting, representing, storing, and retrieving information. Communication presumes transfer of the information retrieved to the subsystem which requires this information. Creation is generation of new knowledge which is based upon information retried. In most cases, generation of new knowledge is assumed to be the core process of decision making during planning and/or lower level control operations. Finally, utilization is using this information to provide the required changes. Certainly, this quadruple is performed as a response to a set of input specifications which are expected to achieve a definite result.

There are two bodies of knowledge representation:

1. fundamental science-oriented, and

2. control-oriented

In the first one, all items of knowledge are considered equally important. The second focuses on items of knowledge which are particularly important for the achievement of the desired results. Fundamental science-oriented models are comprehensive and include all information. Knowledge representation based on fundamental science-oriented models must be carried out off-line. Whereas in control-oriented knowledge representation a compression of knowledge is imposed; what is needed is a reduction and focusing of the relevant information to ensure interactive simulation. This, in contrast, can be carried out on an on-line basis. Thus, it is proposed that these two views, those of the control engineer and the materials engineer, be united. In the conceptual framework of this article, the "world" is described, discussed, and utilized at two (and sometimes three) resolutions simultaneously. The field of materials processing is treated as a multi-resolutional system and the controller as a multiresolutional knowledge-based controller. In addition to this concept, the methodology of on-line multi-resolutional learning without a "teacher" is a new concept for both control and materials processing fields.

Knowledge may be defined as a system of structured information interpreted within a context. Knowledge of a given process is really a system of interrelated labels given to the various sets of information, and each of these labels has its own explanation. The information can subsequently be decomposed into a set of other labels which respectively have other explanations.

Unfortunately, more than one explanation usually exists for a label, or a system of labels. Different explanations represent different facets of the 
system: some of these seem to be unnecessary and are called redundant. It is difficult to decide a priori which of the explanations is necessary for problem solving. Thus, the adequate knowledge sphere is presumed to be contained within the complete set of various explanations together with the links between these various explanations.

Representation of knowledge should be multi-resolutional. Several levels of resolution (abstraction, generalization) have to be maintained simultaneously. These form a hierarchy (pyramid, tree) of interrelated and repetitive descriptions of the same system. This can be thought of as a multi-grid structure of representation. Each of the girds describes the same system at a different scale of the grid. At different resolutions, different entities can be distinguished within the system of coordinates for a tessellation which describes the system with particular accuracy.

It is not customary to organize knowledge in a form of multi-resolutional hierarchies with heterarchical connections. This is the way which turned out to be convenient in the computer paradigm. Historically, several techniques were developed for putting knowledge into a convenient form, such as mathematics (algebraic, and/or differential and integral equations together with the respective solutions in the form of formulae and computational procedures) and/or a variety of logics. Thus, knowledge transfer may take place via:

- mathematical models

- linguistic models (such as sets of logical and/or descriptive statements, empirical rules)

- a combination of both

It is the case that both methods, mathematical models as well as rulebased representations, are substantially incomplete. Since these methodologies describe incomplete knowledge, the representations turn out to be inadequate. Mathematical modelling is more often incomplete than the set of rules because in order to make elegant mathematical models some knowledge has to be sacrificed. When one makes lists of rules, one does not have to sacrifice data and furthermore, one can add as many rules as one wants.

Rules in this context mean a logical statement which may be described in words by applying operators of generalization, and implication to the labels describing objects and their parts, as well as relationships among 
them. The statements of existence together with the statements of belonging to a class generate IF THEN clauses, or rules which represent the sets of connected weighted thoughts about a time-related process.

The set of rules known from experience often contains more information than a system of equations. It is possible to group all the expert-generated knowledge into a form of rules. Learning presumes repetition of similar observations. The system comprises recognizing the phenomenon of similarity and assigning the status of rule to the time. The more often the item is observed, the more valid will be the rule. Thus, the schemes used for fighting ignorance are through redundancy which can be gained from experience, eg via learning, Figure 1.

The learning-by-redundancy scheme requires that all information is included in the system of knowledge organization even though at times some of the data are thought to be unnecessary. It is through this redundancy that one can learn and develop a knowledge base that is truly a holistic model of the process, and which represents all causalities of the system which perhaps may not be evident from the conventional deductive process.

Figure 2 shows a plant and its controller, which in this context is the metallurgical process together with a concrete technological environment including the machine environment, and the infrastructure pertaining to the machine. The process is equipped with a set of actuators and sensors. Actuators are all devices which can change one or more process variables following external commands. Sensors measure the observables. Both the set of commands to the actuators, and the set of sensor outputs are the socalled design inputs to develop a procedure which allows for obtaining (computing) the actuator inputs from the sensor outputs by virtue of some algorithm called the control algorithm. If this is done off-line, the process of control turns out to be predetermined by the off-line decisions of the design engineer. This is fine if the process is well known and well understood, although this is unfortunately often not the case.

The fact that the structure of properly organized knowledge will be the source of control information makes this process knowledge based. The fact that the controller is not using the existing models of knowledge but builds them all along as part of the process, makes the process an intelligent one. If the described set of procedures, called design of control, is carried out on-line it is called a controller, and if the two premises given above are satisfied then it will be an intelligent knowledge based controller. It became clear that this controller must continuously correct 


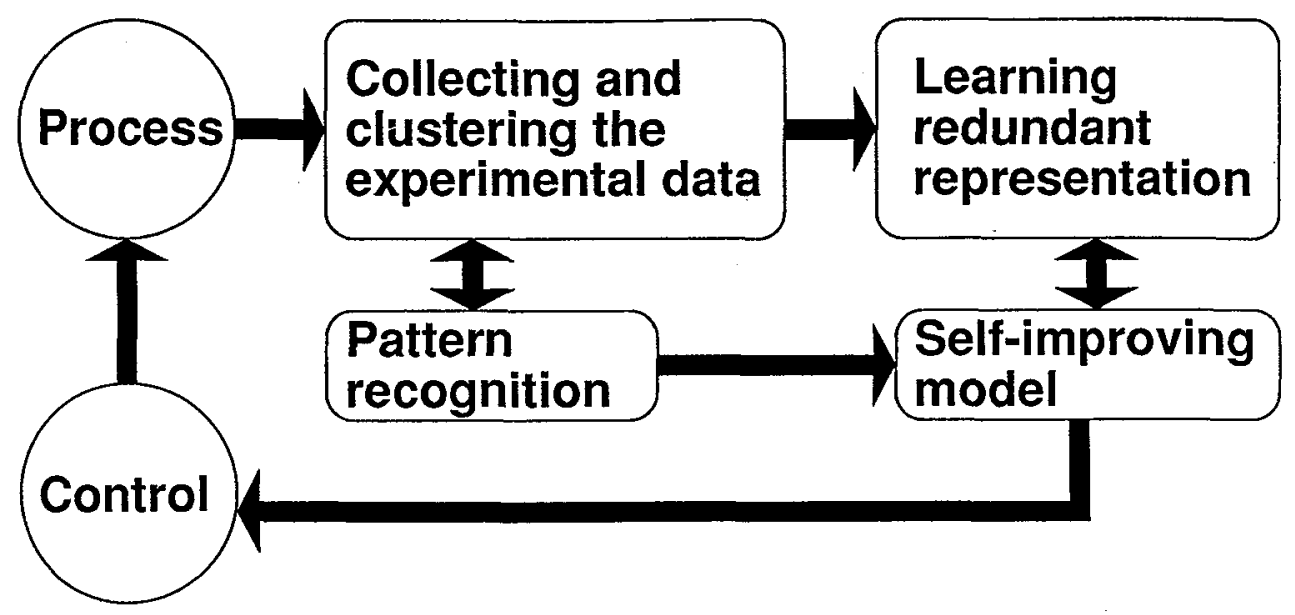

Figure 1: Learning by Redundancy

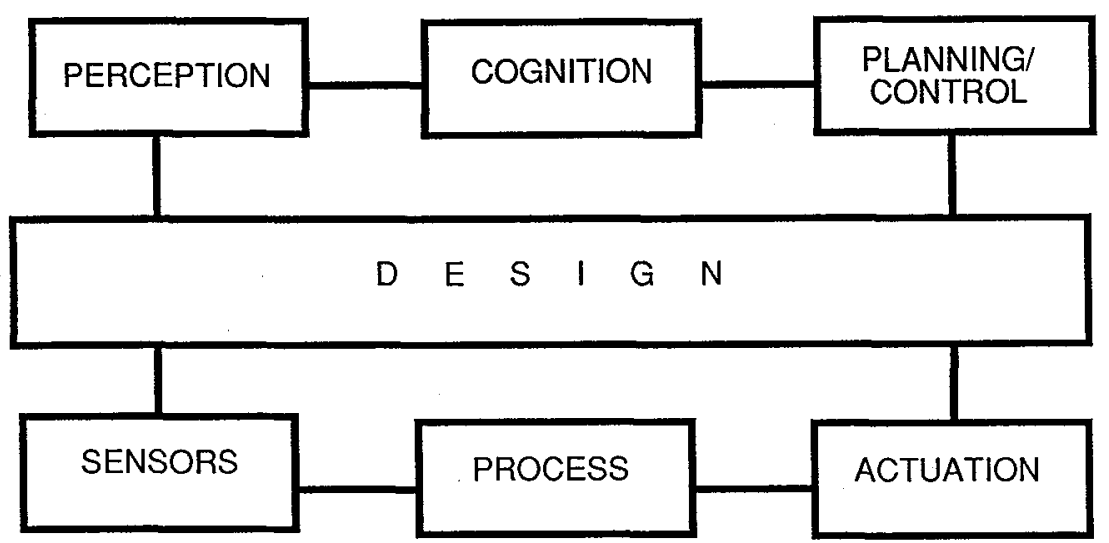

Figure 2: The Concept of Intelligent Controller 
the information on the process: generalizing this information, improving the models, and computing control sequences - exactly what a good engineer must do in the trivial off-line design.

\section{APPLICATIONS}

Though some of these concepts may be abstract, much progress has been made to incorporate knowledge engineering based methodologies in the world of materials processing. Specific examples where intelligent processing approaches have been introduced and are under continuous development:

- Metal casting industries - i.e., aluminum foundries and the use of thermal analysis to control grain refinement and modification.

- Continuous casting of steel - i.e., on-line chemical analysis of the molten metal; detection of cracks during solidification; detection of the liquidus isotherm through ultrasonic sensors.

-Welding - i.e., monitoring the weld pool length and its motion.

- Spray deposition - i.e., process controls in a complex new development such as the Osprey process, where many variables need to be monitored and controlled concurrently.

- HIP processing - i.e., monitoring of the last pores to sinter and thus to assess on an on-line basis density of the final component.

Because of the constraints of time limits of this address, I will be unable to go into each of the above examples. However, I would like to take the opportunity to review one specific application wherein intelligent processing methodologies have made significant contributions in the improvement of the end product and in controlling the process.

In plasma deposition, powder particulates are injected into the plasma torch and the particles are melted within the plasma which can be thought of as a plume of ionized gas traversing at high velocities and being an enthalpy source. The various zones within the plume are noted in Figure 3 , Zone 3 being the area where the particles impact the substrate and consolidation of the melted droplets takes place. Process understanding and knowledge engineering of the system is carried out by segmenting the process in its various logical steps. In the subsequent step, each of the parameters identifed in Figure 3 are further dissected with respect to 


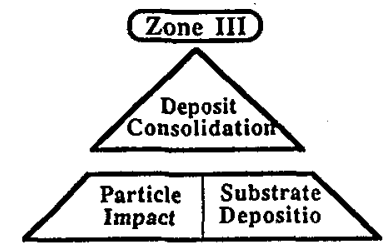

Zone II

\begin{tabular}{|c|c|c|}
\hline Relative & Particle & Substrate \\
Deposit Motion & Trajectory & Temperature \\
\hline
\end{tabular}

Zone D

\begin{tabular}{|c|c|c|c|}
\hline $\begin{array}{c}\text { Arc } \\
\text { Initiation }\end{array}$ & $\begin{array}{c}\text { Torch / Jet } \\
\text { Stabilization }\end{array}$ & $\begin{array}{c}\text { Particle } \\
\text { Injection }\end{array}$ & $\begin{array}{l}\text { Environment } \\
\text { Stabilization }\end{array}$ \\
\hline & Preselected \\
\hline \begin{tabular}{c|c|c|c|} 
Particle \\
Size / Comp.
\end{tabular} & $\begin{array}{c}\text { Substrate } \\
\text { Shape / Surface }\end{array}$ & $\begin{array}{c}\text { Torch / Nozzle } \\
\text { Design }\end{array}$ & $\begin{array}{c}\text { Arc Gas } \\
\text { Composition }\end{array}$ \\
\hline
\end{tabular}

\section{Figure 3: The Process Elements in Plasma Spray Deposition}

process parameters and variables. For example, in Zone 1 for the torch/jet stabilization, one would consider plasma temperature, plasma velocity, plasma density, oscillations and expansion. In Zone 3, for substrate deposition, the parameters which one would consider would be deposit shape, thickness and heat flux.

Figure 4 shows the intelligent controller model where the control program sequence is influenced by both on-line knowledge-base controller as well as an off-line knowledge base program generator. The learning which occurs during processing through the feedback mechanism which has been put in place is a new paradigm for materials processing engineers since we have moved to a different plateau of achieving the end product through an effective processing route.

\section{FUTURE CHALLENGES}

There are many challenges facing the community of materials processing engineers. The decade of the $90 \mathrm{~s}$ will be viewed by historians as a decade of change. Transitions are taking place not only in political and cultural circles but also in the technology of processing. The information age has allowed us to manipulate data which yields information and from which knowledge is generated. The change taking place in our discipline is one where we are asking and searching for the ultimate - control of 


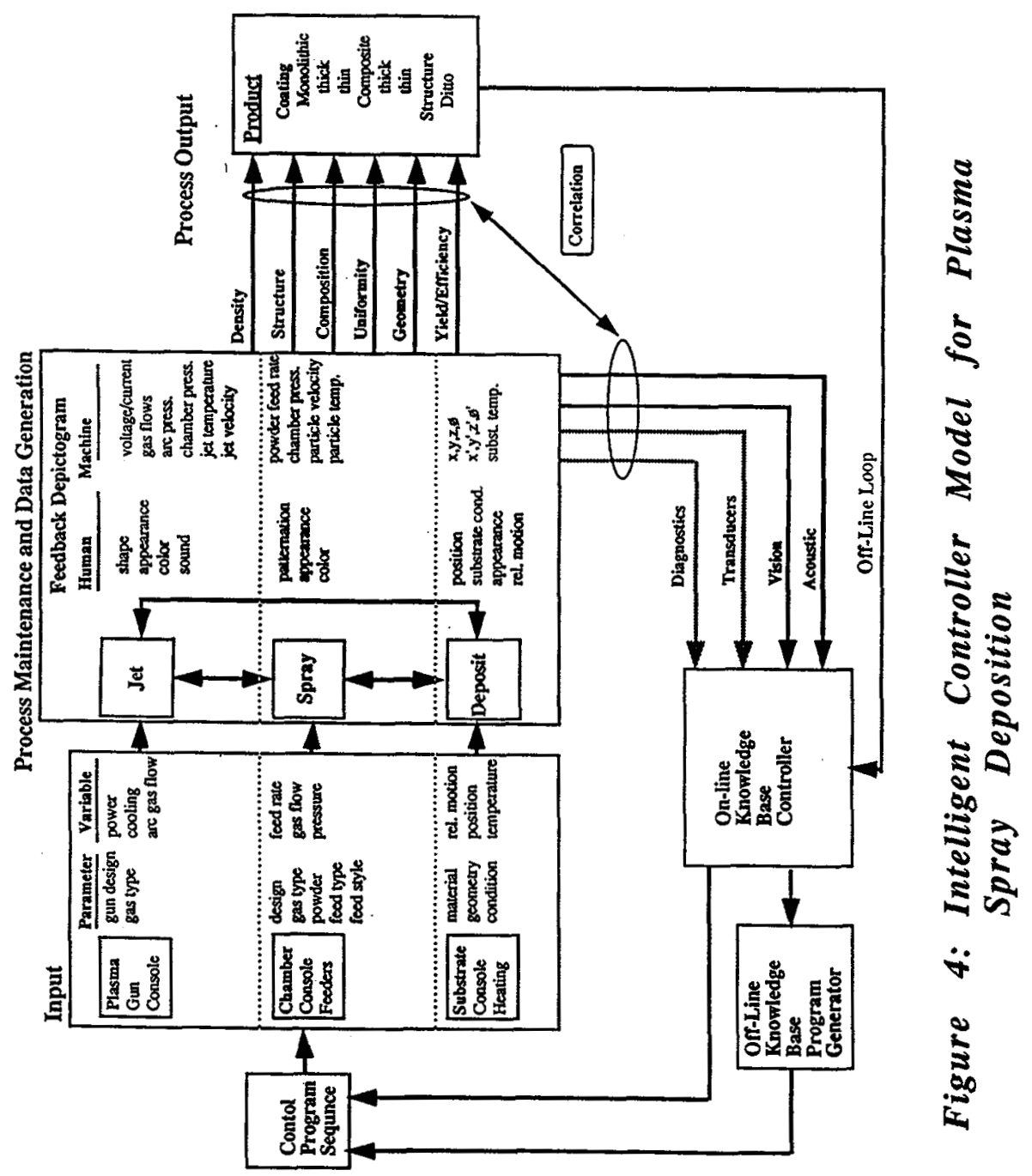


composition and microstructure from melt to final product...in the most efficient and effective manner possible. Figure 5 shows the progress we have made and where intelligent processing of materials (IPM) fits within this sequence of progressions starting from the blacksmith shop. The challenges we face include the development of robust and viable sensors; the ability of integration and fusion of the data (sensor fusion) and educating a new genre of processing engineers who appreciate and understand the need of process control in the dawn of the 21 st Century.

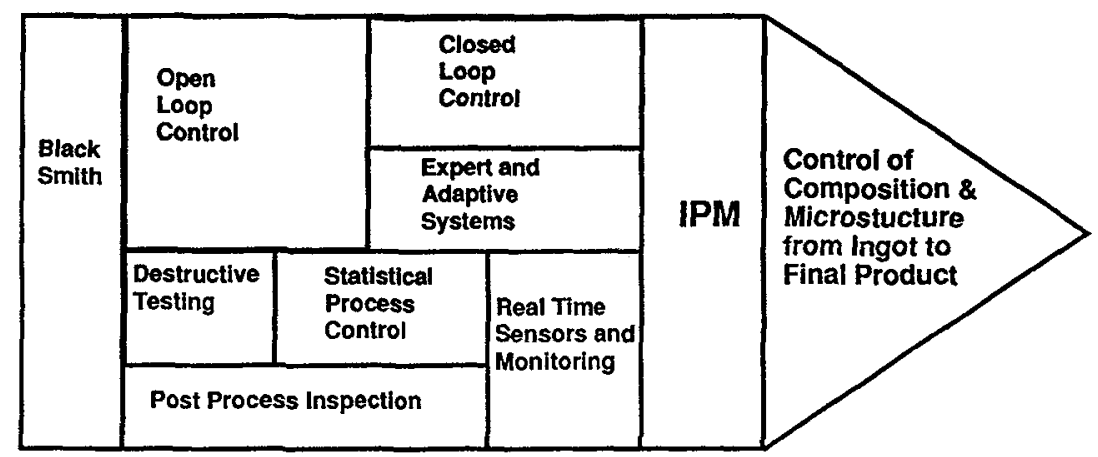

Figure 5: Development of Processing Understanding and the Role of IPM - Intelligent Processing of Materials 